\title{
Does Direct Inhibition Bring Direct Benefit?
}

\author{
Shichiro Abe, MD; Isao Taguchi, MD; Teruo Inoue, MD
}

$\mathbf{I}$ $\mathrm{n}$ this issue of the Journal, Ozaki et $\mathrm{al}^{1}$ provide the first noteworthy evidence of the beneficial effect of the direct renin inhibitor (DRI), aliskiren, combined with reninangiotensin system (RAS) inhibitors in the myocardial recovery process of early acute myocardial infarction (AMI). It is well-known that RAS inhibitors protect against myocardial damage in patients with AMI, but the role of DRIs in myocardial salvage after AMI has not been elucidated. The authors previously reported the negative association of the peak level of $\mathrm{CD} 14^{+} \mathrm{CD} 16^{-}$monocytes, which potentially differentiate into M1-type macrophages, with the extent of myocardial salvage after AMI. In the present study they demonstrate the additive myocardial salvage effect of DRI in combination with RAS inhibitors, which was assessed using cardiac MRI, in negative association with the peak level of CD14+CD16- monocytes.

\section{Article p 1461}

ATII is known to be generated via 2 cascades: the angiotensin-converting enzyme (ACE)-dependent cascade and the ACE-independent one such as mast cell-derived chymase. ${ }^{2}$ It had been assumed that angiotensin-receptor blockers (ARBs) might be superior to ACE inhibitors (ACEIs) for treating cardiovascular disease, because ACEIs can inhibit the RAS system but not chymase. Nevertheless, there is no established evidence of the superiority of ARBs over ACEIs for secondary prevention in patients with MI. In the latest guidelines, ACEIs but not ARBs are recommended as the first-choice RAS inhibitor. Although some investigators have reported that combination therapy with ACEIs and ARBs might improve the morbidity and mortality of cardiovascular diseases, there is no established effectiveness of their combination in the results of large clinical trials. Because both ACEIs and ARBs inhibit downstream of RAS, renin activity is accelerated by the negative feedback response. In contrast, DRI is upstream RAS inhibition therapy, so it may possibly intervene in the negative feedback response by downstream blocking, and thus would be expected to enhance the organ protective effect, when added to an ACEI or ARB. ${ }^{3}$ The Aliskiren Observation of Heart Failure Treatment (ALOFT) investigators added alisikiren or placebo on ACEIs/ARBs plus $\beta$-blockade in hypertensive patients with heart failure. ${ }^{4}$ In the aliskiren group, the level of B-type natriuretic peptide (BNP) decreased significantly. However, they reported that aliskiren could not improve remodeling of the left ventricle (LV) in AMI patients with low LV ejection fraction. Now, we need to keep in mind that the administration of a DRI plus RAS inhibitor is contraindicated for patients with type 2 diabetes and a moderate or severe grade of chronic kidney disease because of adverse events that include hypotension, faintness, stroke and hyperkalemia. There is much evidence of the effectiveness of ACEIs and ARBs beyond blood pressure lowering, so clinical trials using DRI are usually designed as an add-on. The Aliskiren and Valsartan to Reduce NT-proBNP via RAS blockade (AVANT GRADE)-TIMI43 investigators demonstrated that aliskiren had no myocardial salvage effect on patients with early acute coronary syndrome within 30 days significantly. ${ }^{5}$ On the other hand, the Aliskiren in Left Ventricular Hypertrophy (ALLY) trial investigators concluded that aliskiren was as effective as losartan in promoting LV mass reduction in hypertensive patients with LV hypertrophy, ${ }^{6}$ indicating that DRIs may independently have therapeutic potential for some morbid conditions of cardiovascular disease. Notably, the present study suggests that adding a DRI to RAS inhibitor therapy may be effective for patients with early AMI, especially in the Japanese population. We may have heard a new ringing of the bell.

\section{References}

1. Ozaki Y, Imanishi T, Tanimoto T, Kashiwagi M, Tsujioka H, Sougawa $\mathrm{H}$, et al. Effect of direct renin inhibitor, aliskiren, on peripheral blood monocyte subsets and myocardial salvage in patients with primary acute myocardial infarction. Circ J 2012; 76: 1461 - 1468.

2. van Giest WH, de Graff PA. Early ACE-inhibition in myocardial infarction: Possible role of bradykinin. Agent Actions Suppl 1992; 38: $80-89$.

3. Ichihara A, Sakoda M, Kurauchi-Mito A, Narita T, Kinouchi K, Bokuda K, et al. New approaches to blockade of renin-angiotensinaldosterone system: Characteristics and usefulness of the direct-renin inhibitor aliskiren. J Pharmacol Sci 2010; 113: 296-300.

4. McMurray JJV, Pitt B, Lantini R, Maggioni AP, Solomon SD, Keefe DL, et al; Aliskiren Observation of Heart Failure Treatment (ALOFT) Investigators. Effects of the oral direct renin inhibitor aliskiren in patients with symptomatic heart failure. Circ Heart Fail 2008; 1: $17-24$.

5. Scirica BM, Morrow DM, Bode C, Ruzyllo W, Ruda M, Oude Ophuis AJ, et al. Patients with acute coronary syndromes and elevated levels of natriuretic peptides: The results of the AVANT GRADE-TIMI 43 Trial. Eur Heart J 2010; 31: 1993-2005.

6. Salomon SD, Appelbaum E, Manning WJ, Verma A, Berglund T, Lukashevich V, et al; Aliskiren in Left Ventricular Hypertrophy (ALLAY) Trial Investigators. Effect of the direct renin inhibitor aliskiren, the angiotensin receptor blocker losartan, or both on left ventricular mass in patients with hypertension and left ventricular hypertrophy. Circulation 2009; 119: 530-537.

The opinions expressed in this article are not necessarily those of the editors or of the Japanese Circulation Society.

Received April 18, 2012; accepted April 18, 2012; released online May 10, 2012

Department of Cardiovascular Medicine, Dokkyo Medical University, Tochigi, Japan

Mailing address: Shichiro Abe, MD, Department of Cardiovascular Medicine, Dokkyo Medical University, Kitakobayashi, Mibu-machi,

Tochigi 321-0293, Japan. E-mail: abenana@dokkyomed.ac.jp

ISSN-1346-9843 doi:10.1253/circj.CJ-12-0516

All rights are reserved to the Japanese Circulation Society. For permissions, please e-mail: cj@j-circ.or.jp 